\title{
A educação das relações étnico-raciais no contexto da educação física: reflexões sobre a disciplinarização, o silenciamento e suas possibilidades
}

\author{
Ethnic-racial relations education in the context of physical education: \\ reflections on the disciplining, silencing and your possibilities
}

Keylla Amélia Dares Silveira Especialista em EducaçãoFísica Escolar - IF Sudeste MG Mestranda no Programa de Pós-Gradação em Educação Universidade Federal de Juiz de Fora - UFJF. Juiz de Fora, MG - Brasil keyllamelia@hotmail.com

Wilson Alviano Júnior Doutor em Educação pela FE-USP Universidade Federal de Juiz de Fora - UFJF. Juiz de Fora, MG - Brasil. wilson.alviano@ufjf.edu.br

Resumo: Este estudo tem como objetivo apresentar algumas reflexões acerca da temática da Educação das Relações Étnico-Raciais e seu elo com a Educação Física. Para tanto, utilizamos como ferramenta a pesquisa bibliográfica. A Educação Física, enquanto componente curricular da Educação Básica, esteve por muito tempo vinculada aos interesses de instituições médicas e militares que definiam seu espaço e campo de conhecimento. Nesse contexto, sua atuação tencionava a formação e a manutenção de corpos disciplinados, fortes e saudáveis, seguindo preceitos como os da eugenia, por exemplo. Nesse tipo de intervenção, as manifestações afro-brasileiras e indígenas eram invisibilizadas, marginalizadas e oprimidas, em detrimento à reprodução de modelos eurocêntricos de expressões corporais. Diante disso, argumentamos a favor de um currículo de Educação Física pautado nos conhecimentos oriundos de diferentes populações, sobretudo dessas que foram historicamente silenciadas e que protagonizam a estrutura nossa identidade.

Palavras chave: educação das relações étnico-raciais; educação física.

Abstract: This study aims to present some reflections on the theme Education of Ethnic-Racial Relations and its link with Physical Education. For that, we use bibliographic research as a tool. Physical Education as a curricular component of Basic Education was for a long time linked to the interests of medical and military institutions, which defined its space and field of knowledge. In this context, its work intended the formation and maintenance of disciplined, strong and healthy bodies, following precepts such as eugenics, for example. In this type of intervention, Afro-Brazilian and indigenous manifestations were made invisible, marginalized and oppressed, to the detriment of the reproduction of Eurocentric models of bodily expressions. Therefore, we argue in favor of a Physical Education curriculum based on knowledge from different populations, especially those that have been historically silenced and that play a leading role in the structure of our identity.

Key-words: ethnic-racial relations education; physical education.

\section{Cite como}

\section{(ABNT NBR 6023:2018)}

SILVEIRA, Keylla Amélia Dares; ALVIANO JR, Wilson. A educação das relações étnico-raciais no contexto da educação física: reflexões sobre a disciplinarização, o silenciamento e suas possibilidades. Dialogia, São Paulo, n. 39, p. 1-15, e20452, set./dez. 2021. Disponível em:https://doi.org/10.5585/39.2021.20452.

American PsychologicalAssociation (APA)

Silveira, K. A. D., \& Alviano Jr, W. (2021, set. /dez.). A educação das relações étnico-raciais no contexto da educação física: reflexões sobre a disciplinarização, o silenciamento e suas possibilidades. Dialogia, São Paulo, 39, p. 1-19, e20452. https://doi.org/10.5585/39.2021.20452. 


\section{Introdução}

Ampliar o diálogo acerca da educação para as relações étnico-raciais faz-se necessário quando almejamos uma sociedade e uma educação que se pretendam democráticas, baseadas no princípio da equidade. Trata-se de uma discussão extensiva, que envolve diferentes pontos que demandam esforços, como: a constituição das identidades de diferentes grupos; a pesquisa e a sistematização de conhecimentos e culturas historicamente construídos e reconstruídos pelos povos que, por muito tempo, foram oprimidos e silenciados; o lugar ocupado por esses grupos nas diferentes esferas da sociedade, especialmente nas instituições educacionais; suas principais lutas e conquistas no que se refere às políticas públicas; as possibilidades de intervenção no escopo das reparações; entre outros. Concebemos todas essas questões como valiosas e imprescindíveis nos debates do campo da Educação e da Educação Física. Contudo, em virtude das condições objetivas impostas ao tipo de pesquisa aqui apresentada, tecemos argumentações que se aproximam do elo construído entre as culturas e as histórias afro-brasileiras e indígenas e a Educação Física enquanto disciplina escolar.

Identificamos, previamente, nas descrições historiográficas do século XIX o controle, o silenciamento e o apagamento das experiências dos povos indígenas originários e dos africanos escravizados e seus descendentes, sendo o primeiro grupo retratado usualmente apenas no contexto da "colonização" do nosso país, e o segundo enquanto sujeitos submetidos à escravização. De acordo com Mattos (2020), esse silenciamento se estabelece em várias instâncias, como, por exemplo, pelo silenciamento constitucional; pelo silenciamento da presença dos atores políticos africanos e afrodescendentes em suas diferentes formas de resistência; pelo silenciamento do contrabando; entre outros.

Fomentando esse diálogo, Abreu (2020) descreve que a história do Brasil escrita por mãos brancas negligencia fatos importantes e deforma muito a história do negro, tratando basicamente da escravidão como única narrativa e ocultando outras formas de o negro viver no Brasil - como, por exemplo, o processo de alforria, que existiu em todo o período de escravidão; a constituição dos quilombos; as produções culturais; entre outras. Desse modo, a história das vivências negras foi por muito tempo unificada a partir do racismo, mesmo com as tantas liberdades e tantas experiências diferentes do ser negro que existiam. A política republicana reúne essas vivências em uma narrativa única de marginalização, contada a partir da experiência do fracasso. A autora aponta que não devemos relegar a existência da escravidão, a marginalização e a discriminação como uma realidade, contudo essa não foi a única história de negros e negras no Brasil. 
Igualmente, Pinto (2020) defende que, para empreender uma educação antirracista e um estudo crítico a respeito dessas histórias de negros e negras, devemos partir das vivências de grupos livres, que narram suas existências, mesmo que nessa sociedade tenham existido escravos. Precisamos, então, estudar a liberdade negra para podermos escrever histórias consistentes sobre o racismo como algo estruturante no Brasil, que tem a ver com cultura, com as maneiras racializadas e hierarquizadas que este país estabelecia para se relacionar com os seus sujeitos. Para Albuquerque (2020), o silenciamento das experiências negras envolve ainda outras questões. A autora reconhece que não houve desamparo por parte do Estado com a população negra, pois a construção de uma sociedade racializada era um projeto político, isto é, o Estado Republicano se constituiu para reafirmar a desigualdade racial, estabelecendo, então, um plano, e não uma falha. Albuquerque (ibidem) exemplifica ainda algumas conexões do passado com o presente, como a precarização da liberdade negra, remetendo aos tempos da escravidão - em que um indivíduo negro poderia ser "confundido" e dado como sujeito escravizado, caso não comprovasse sua liberdade - e relacionando a algumas situações cotidianas de violência que envolvem homens e mulheres negros e negras em nosso atual sistema de segurança pública.

Em consonância com essas autoras e com a proposta de não reduzir a existência da população negra à história da escravidão, e da população indígena ao período da "colonização", concebemos ser necessário o diálogo acerca das (re)construções e manutenção de suas expressões culturais, sobretudo no que se refere às manifestações corporais que foram por tanto tempo preteridas e até proibidas nos diferentes espaços sociais.

Apoiados nesse contexto e em uma revisão bibliográfica, desenvolvemos este artigo com o objetivo de sublinhar, à luz de algumas reflexões, como a Educação Física se constituiu enquanto instrumento disciplinador e hierarquizador de corpos - a partir de preceitos eugênicos e higiênicos - e qual é o seu papel no processo de reparação das desigualdades por ela produzidas.

2 Percurso da Educação Física no século XIX e as relações étnico-raciais: das formulações europeias à estruturação dessa disciplina escolar no Brasil

A história da Educação Física no Brasil, desde sua origem até os dias atuais, esteve vinculada à formação social do nosso país e às relações de poder entre os diferentes grupos. Além disso, houve uma influência expressiva de referenciais europeus na constituição dessa disciplina escolar, o que favoreceu a intervenção da EF nas escolas sob condutas de opressão e de alijamento das produções dos corpos não brancos.

Compondo esse cenário, o Brasil investiu e dedicou-se - através dos grupos hegemônicos no poder - na apropriação de elementos inerentes aos modos de vida europeus, sejam aqueles 
relacionados aos sistemas de produção; aos valores culturais, cívicos, morais, higiênicos; e até ao anseio em obter uma população "mais branca", utilizando-se de políticas de branqueamento. Dito isso, torna-se relevante perceber como esses elementos europeus influenciaram a formação social brasileira e a construção da Educação Física no país.

Compreende-se o século XIX na Europa como o período marcado pelas formulações e demarcações de alguns conceitos importantes para o estabelecimento da Educação Física. Nesse período houve a consolidação do Estado burguês e da divisão e hierarquização de classes sociais. Ocorreu também, por parte da burguesia, a pretensão da construção de um novo homem que pudesse sustentar essa nova ordem política, econômica e social (SOARES, 2007). Nessa conjuntura, as desigualdades sociais eram fundamentais para o avanço da organização dessa sociedade capitalista, sendo a classe operária alijada dos centros de governo, se colocando às margens das cidades. Para Hobsbawn (1982 apud SOARES, ibidem) "o desenvolvimento urbano foi um gigantesco processo de segregação de classes".

A partir desse cenário de mudanças de paradigmas, a ciência passou a ser produtora legítima de conhecimento. Desse modo, para a construção do novo homem - essencialmente biológico/produtivo - a burguesia apoiou-se nas teorias positivistas, com o argumento de que os corpos das classes operárias, por não serem habituados a regras, precisavam de "disciplina" e “adestramento" (SILVA, 2019). Assim, o corpo passa a ser conferido como mercadoria, tornandose imprescindível mantê-lo forte e saudável para corresponder às exigências do capital, entendendo o vigor físico dos trabalhadores como essencial para o avanço e sucesso da sociedade capitalista. Nesse contexto é que os investimentos direcionados ao corpo e ao seu rendimento se consolidaram.

Ainda nesse panorama, a eugenia revelou-se como ciência para justificar as desigualdades e legitimar a exploração de classes e raças, além de buscar comprovar a ideia do "melhoramento" e da "depuração" da raça, utilizando de preceitos biológicos para explicar a humanidade. Outrossim, o discurso médico higienista integrou profundamente as ações da burguesia. Constituindo-se de caráter moralizador, normativo e educativo, o higienismo posicionou-se a fim de alterar hábitos, costumes, crenças e valores dos grupos subalternizados, promovendo o que denominavam de "assepsia social".

Soares (2007) reconhece a educação como um fenômeno que não se isola das demais políticas sociais, integrando, portanto, de modo orgânico, as formas de difusão de uma determinada mentalidade dominante, homogeneizando as vontades, os hábitos e criando uma coesão social. Desse modo, a escola e o ensino destinados à população subalternizada foram idealizados e 
caracterizados a partir de vertentes legitimadas pela burguesia. Diante disso, a autora revela ainda que as educações física, moral, intelectual e sexual foram utilizadas pela burguesia como ferramentas para incorporar essa concepção higienista.

Pontualmente nesse contexto é que a Educação Física, à época denominada "Ginástica”, foi veiculada como instrumento capaz de promover a almejada "assepsia social", viabilizando nas escolas a educação eugênica, médica e higiênica. Ao dirigir ao corpo uma abordagem de caráter biológico, a-histórico, conservador e utilitário, a Educação Física limitou o entendimento do "homem", fazendo com que o "homem social" fosse reduzido a "biológico", o que favoreceu e reforçou expressivamente as teorias raciais (SOARES, 2007).

Destarte, esse componente curricular apoiou-se nos ideais do positivismo e do liberalismo, apontando interesse pelas leis, normas, hierarquia, disciplina e organização da forma. Soares (ibidem) indica que do positivismo a Educação Física incorporou com propriedade sua concepção de homem como um ser puramente biológico e orgânico, determinado por caracteres genéticos e hereditários. Já do liberalismo herdou as "regras" para os esportes modernos, dando-lhes a aparência de serem "universais", o que permite a todos vencer no jogo e na vida pelo próprio esforço e capacidade, responsabilizando unicamente o indivíduo pelo seu sucesso ou fracasso.

Ainda no início do século XIX na Europa, a Educação Física foi sistematizada através dos "métodos ginásticos", que correspondiam aos quatro países originários dessas primeiras organizações: Alemanha, Suécia, França e Inglaterra. Denominados também como “escolas”, esses métodos possuíam finalidades semelhantes, como a de regenerar a raça; promover a saúde; desenvolver a coragem, a força, e energia vital - para servir a pátria e a indústria; e desenvolver a moral (SOARES, ibidem). Foram métodos que inspiraram vigorosamente a ação da Educação Física brasileira.

Igualmente como na Europa, houve no Brasil a conformação de uma nova ordem econômica, política e social, estabelecendo a necessidade de construção do também "novo homem". Precedente a essa nova conformação, ainda no período colonial, surgiram aqui no país preocupações relativas ao corpo, à saúde e à higiene das elites dirigentes. Soares (ibidem, p. 72) revela que

\footnotetext{
Não interessava ao Estado modificar o padrão familiar dos escravos que deveriam continuar obedecendo ao código punitivo de sempre. Os escravos, juntamente com os desclassificados de todo tipo, serão trazidos à cena como aliados na luta contra a rebeldia familiar [...] A eles vão ser dedicadas outras políticas médicas. Foi sobre as elites que a medicina fez incidir sua Política familiar, criticando a família colonial nos seus crimes contra a saúde (SOARES, 2007, p. 72).
} 
A justificativa a essa "política familiar" deu-se pelas precárias condições de saúde, e pelos altos índices de mortalidade infantil na sociedade brasileira. Para viabilizá-la, os higienistas valeramse da chamada "ginástica", pois através dela poderiam favorecer a construção representativa da classe dominante/branca, atribuindo-lhe superioridade. Ainda nesse contexto, as elites dirigentes forjavam e acentuavam o caráter "irracional", "bárbaro" e "primitivo" dos negros, reforçando sua inferioridade e configurando-os como ameaça. Esse percurso fomentou o racismo e os preconceitos a ele ligados, consolidando ainda mais a manutenção dos polos de exploração de uma formação social escravista (SOARES, 2007). Munanga (1999) refere-se ao racismo como uma construção ideológica produzida socialmente e intensamente enraizada na sociedade brasileira, sendo uma "patologia colonial" apresentada através de preconceitos, discriminações e estereótipos.

A partir da segunda década do século XIX, momento em que metade da população que aqui vivia era composta por escravizados, houve um acentuado esforço para implementar o projeto de eugenização da população brasileira. Influente defensor da eugenia no Brasil, Fernando de Azevedo a definia como

\begin{abstract}
A ciência ou disciplina que tem por objetivo o estudo dos fatores que, sob o controle social possam melhorar ou prejudicar mentalmente, as qualidades raciais das gerações futuras; ou por outras palavras, o estudo das medidas sociais, - econômicas, sanitárias e educacionais que influenciam, física e mentalmente, o desenvolvimento das qualidades hereditárias dos indivíduos e, portanto, das gerações (SOARES, 2007, p.120).
\end{abstract}

$\mathrm{Na}$ conjuntura dessa teoria, negros e indígenas estavam fadados ao desaparecimento por serem considerados inferiores. Renato Kehl - outro articulador e incentivador do movimento eugenista no Brasil - corroborou com essa ideia quando defendeu que

Ninguém poderá negar que no correr dos anos desaparecerão os negros e os índios das nossas plagas, assim como os produtos resultantes dessa mestiçagem. A nacionalidade embranquecerá à custa de muito sabão de coco ariano (SILVA, 2019, p. 51).

Kehl ainda admitia como necessário

Restringir a proliferação de infra-homem, de semi-alienados e de dementes, pela higiene do corpo e espírito [...] [além de] fazer com que pessoas fortes, equilibradas, inteligentes e bonitas, tenham um maior número de filhos, para que o número médio destas pessoas [...] se eleve progressivamente (SOARES, 2007, p. 121).

Retratada como ferramenta aliada aos preceitos eugênicos, a Educação Física mostrou-se fundamental para o projeto de regenerar e revigorar racialmente o Brasil. Do mesmo modo, o movimento higienista valeu-se das intervenções dessa disciplina que, em suas primeiras investidas a fim de compor o espaço escolar, revelou-se como instrumento de promoção da saúde física e 
mental, da educação moral, e da reconstituição das raças, privilegiando em suas propostas pedagógicas princípios estritamente biológicos.

Ainda no período que compreende o Império no Brasil, a escola elementar foi designada aos filhos das elites, reservando a estes uma educação física "apurada", associada à educação sexual para transformar homens e mulheres em potenciais reprodutores e vigilantes da "pureza" de sua própria raça (SOARES, ibidem).

Já nos limites transitórios do Império à instalação da República, suscitou-se no Brasil um conjunto de processos renovadores que revelavam um capitalismo incipiente - esse período envolveu a abolição da escravidão; processos de implementação do trabalho assalariado; modernização das lavouras; e abertura das primeiras indústrias no país. A partir disso as elites inauguraram interesse pela educação da classe trabalhadora, dispondo da instrução como algo necessário à integração e incorporação das populações subalternizadas aos processos civilizatórios característicos da sociedade capitalista (SOARES, ibidem).

É oportuno mencionar que nesse período, com o fim do sistema escravista, a construção de uma nação e de uma identidade nacional surge como uma questão problemática aos intelectuais brasileiros, sobretudo por conta dos ex-escravizados negros como uma nova categoria de cidadãos

Como transformá-los em elementos constituintes da nacionalidade e da identidade brasileira quando a estrutura mental herdada do passado, que os considerava apenas como coisas e força animal de trabalho, ainda não mudou? Toda a preocupação da elite, apoiada nas teorias racistas da época, diz respeito à influência negativa que poderia resultar da herança inferior do negro nesse processo de formação da identidade étnica brasileira (MUNANGA, 1999, p. 51).

Ainda de acordo com Munanga (ibidem), a pluralidade racial representava uma ameaça e um obstáculo para a construção de uma nação que se pretendia branca, estabelecendo a raça como tema central de debate nacional até meados do século XX. As elaborações ideológicas, vestidas de cientificismo - como a eugenia, por exemplo - nos possibilita compreender as dificuldades que a população negra apresentava para constituir uma identidade coletiva e politicamente mobilizadora.

Ainda nas duas primeiras décadas da República, o Brasil sofreu com o alastramento de doenças e com os altos índices de mortalidade, fatos que ameaçavam as forças produtivas tão valorosas à reprodução do capital e, consequentemente, a efetiva implantação do novo regime capitalista. Com base nisso, a educação e a saúde receberam atribuições de destaque no processo de transformação desse quadro ameaçador. A Educação Física nas escolas - que se apresentou como síntese dessas duas práticas sociais (educação e saúde) - poderia sustentar a modificação do modo de vida das populações, estabelecendo o indivíduo forte, saudável, moralmente educado e 
disciplinado, ou seja, a figura basilar para o trabalho fabril da época. Essa disciplina escolar "Podia ser a 'receita' e o 'remédio' para a cura de todos os 'males' que afligiam a caótica sociedade brasileira capitalista em formação" (SOARES, 2007, p. 135). Castellani Filho (2007) acresce que, com preceitos militares e de autoritarismo, a Educação Física acentuava seu caráter instrumental, zelando pela preparação, recuperação e manutenção da força de trabalho.

Mediante ingerência de vieses médico-higienistas e militares, que definiam o espaço e campo de conhecimento da Educação Física, essa disciplina foi reconhecida como mecanismo fundamental na ação e intervenção da realidade educacional e social, promovendo a "educação integral” do ser humano (SILVA, 2019). Para Rui Barbosa "os benefícios que se podiam auferir da ginástica eram inúmeros e, decididamente, de enorme importância para a 'educação' não apenas 'física' do povo brasileiro, mas para a sua 'educação plena', ou seja, moral e intelectual” (SOARES, ibidem, p. 92). Também Fernando de Azevedo, outro apoiador da "Ginástica", afirmava que "um organismo sadio e de músculos adestrados é de certo mais fácil a moralizar do que uma máquina humana enfraquecida e emperrada" (SOARES, ibidem p. 133).

Em Silva (ibidem) há indicação de uma abordagem tecnicista presente nas ações da Educação Física a partir dos anos 1960 aqui no Brasil, apontando para uma educação com fortes influências do regime liberal. Nesse contexto, a tarefa atribuída à escola e à EF seria a de preparar o aluno para exercer funções sociais, principalmente no que diz respeito ao mundo do trabalho. Tratava-se então de uma ação baseada em suas aptidões e habilidades, desinteressada de reflexão, e estritamente de viés biológico. Castellani Filho (ibidem) aponta que:

A compreensão da Educação Física enquanto "matéria curricular" incorporada aos
currículos sob a forma de atividade - ação não expressiva de uma reflexão teórica,
caracterizando-se, dessa forma, no "fazer pelo fazer" - explica e acaba por justificar sua
presença na instituição escolar, não como um campo do conhecimento dotado de um
saber que lhe é próprio, específico - cuja apreensão por parte dos alunos refletiria parte
essencial da formação integral dos mesmo, sem a qual, esta não se daria - mas sim
enquanto uma mera experiência limitada em si mesma, destituída do exercício da
sistematização e compreensão do conhecimento, existente apenas empiricamente. Como
tal, faz reforçar a percepção da Educação Física acoplada, mecanicamente, à "Educação
do Físico", pautada numa compreensão de Saúde de indole bio-fisiológica
(CASTELLANI FILHO, 2007, p. 108).

A Educação Física integrou também o esporte como prática que corporificava os princípios necessários aos indivíduos, sendo fortemente orientada por preceitos da concorrência e do rendimento, mantendo o conhecimento oriundo das ciências naturais para fundamentar suas práticas (BRACHT, 1999). Reiterando essa percepção, Castellani Filho (ibidem) destaca que o povo brasileiro concentrava em torno da Educação Física seus anseios, esperanças e frustrações. O autor discorre ainda sobre o movimento "Esporte para Todos", desenvolvido na década de 70, que aliava 
o desenvolvimento econômico ao desenvolvimento social, confiando esse último à ocorrência do acesso aos esportes para toda a população.

Considerando os referenciais descritos até o momento, notamos que a Educação Física se constituiu, invariavelmente, como espaço para formação e preservação do corpo forte e saudável a partir de uma perspectiva utilitária. Moreira e Silva (2016) afirmam que as diretrizes que orientavam a Educação Física nesse contexto tiveram papel fundamental na construção da matriz racista e na ideologia racial brasileira. Para as autoras, o corpo e o movimento, como criadores de sentidos e significados, foram, por muito tempo, forjados com base nas ideologias de branqueamento, dificultando a incorporação de valores identitários de matriz étnico-racial negra e indígena, e sua apropriação como civilizatórios. Reforçam ainda que

[...] as representações de corpo negro e corpo indígena na escola e na Educação Física seguem ideologias dominantes que historicamente segregaram saberes destas culturas. Isso decorre da percepção de que a Educação Física encontra em seu percurso histórico dificuldades para associar o seu objeto de investigação à questão étnico-racial (MOREIRA; SILVA, 2016, p. 53).

Percorrendo nessa trajetória da Educação Física, identificamos que paulatinamente foram sendo construídas perspectivas essencialmente críticas aos paradigmas da aptidão física e esportiva, que até então sustentavam as práticas dessa disciplina. Em Castellani Filho (2007) verificamos que a década de 1980 se estabeleceu como período de eclosão dessas concepções críticas que, em oposição aos preceitos delineados até então, apropriaram-se de referências das ciências sociais e humanas, para além das biológicas, refutando o reducionismo das formulações tecnicistas. Nesse entendimento, os conhecimentos sobrepujam os limites orgânicos e biológicos, havendo o reconhecimento do ser humano como um ser eminentemente cultural e, desse modo, seus movimentos apresentam-se como fator de cultura.

Para Bracht (1999), essas perspectivas críticas desenrolaram-se em dois momentos, sendo o primeiro deles determinado pelo viés cientificista. Nesse prisma, as ações pedagógicas da Educação Física eram tidas como carentes quanto ao seu embasamento científico, revelando, portanto, os princípios baseados nos estudos do desenvolvimento e da aprendizagem motora. Bracht (1999) deduziu que essa concepção apenas remodelou o percurso até então apresentado pela $\mathrm{EF}$, sem romper efetivamente com os paradigmas da aptidão física e esportiva. O segundo momento citado pelo autor ocupou-se das críticas mais categóricas, incluindo nas discussões da área referências das ciências humanas e sociais. Essa perspectiva suscitou análises quanto à função social da educação e da Educação Física, refletindo vigorosamente sobre o caráter reprodutor da 
escola. O conhecimento é tratado aqui de forma historicizada, e a cultura corporal - objeto inerente de estudo e trabalho da EF - é identificada como um fenômeno histórico-cultural.

A partir da década de 1990 emergiram proposições, sobretudo de tradição marxista, fundamentadas na teorização crítica. Nesse contexto, educar é uma ação política, pois almeja através da socialização do conhecimento historicamente (re)construído - a apropriação, pelas classes populares, de saberes exclusivos à cultura dominante. A Educação Física, por sua vez, tornase um instrumento de libertação, emancipação e transformação, por ser uma área de conhecimento responsável pelos estudos dos aspectos socioantropológicos do movimento humano (CASTELLANI FILHO, 2007). Apoiado nessas proposições, um coletivo de autores mobilizouse para o diálogo e a elaboração de uma das obras mais relevantes da área da Educação Física, o livro "Metodologia do Ensino de Educação Física" que, amparado pela Pedagogia HistóricoCrítica, atribuía ao ensino da EF um caráter crítico.

De acordo com Neira (2011, p. 199), essa perspectiva crítica denunciou as marcas das relações sociais forjadas nos conhecimentos e métodos corporificados na Educação Física, que funcionava como instrumento ideológico na difusão dos princípios dos grupos mais bem posicionados na hierarquia econômica. Sinalizou também a necessidade de uma reflexão acentuada sobre "o quê" era tratado pelos currículos, "a quem" os conhecimentos veiculados pertenciam, “quais" identidades seriam legitimadas por eles e quais seriam negadas, revelando a reprodução da desigualdade pelo sistema educacional e seus desfechos sobre os sujeitos da educação. Inferimos que, a despeito das discussões fecundas na área, a temática étnico-racial não representou uma demanda a ser questionada nessa perspectiva, perdurando as lacunas relativas à essa questão nas elaborações e práticas pedagógicas da Educação Física.

Outras propostas emergiram com o mesmo desacordo aos pressupostos biologicistas até então predominantes da Educação Física. Neira (2011) revela que, reconhecendo a necessidade de ampliar as análises das teorias críticas, e entendendo que as relações de poder operam para além da classe social, as teorias pós-críticas fundamentam uma nova proposta para o trato da Educação Física. Nesse contexto, a ação pedagógica é culturalmente orientada e alicerçada em conceitos como linguagem, diferença e cultura, compreendendo as práticas corporais como produtoras e reprodutoras de significados, que são construídas pelas e nas relações de poder. Outrossim, essa perspectiva não reconhece uma cultura pura, ou sequer melhor, e, desse modo, a escola - por ser um espaço que reconstrói a cultura - não poderia hierarquizar os conhecimentos.

Nessa concepção de Educação Física, há a designação do “currículo cultural” que, referenciado nos Estudos Culturais e no Multiculturalismo Crítico, almeja colocar em ação a 
política da diferença, ou seja, o reconhecimento da cultura corporal de diversos grupos da sociedade. Tenciona também impedir a reprodução da ideologia dominante; posicionar os estudantes como sujeitos da transformação social e contribuir com a construção de uma sociedade mais democrática e justa; promover a "fala" de várias culturas por meio das manifestações corporais, viabilizando a leitura dos grupos hierarquizados pelos sistemas hegemônicos econômico, político, social e cultural; identificar a opressão e subalternização de culturas e sujeitos, erros históricos no processo de formação identitária dos negros, das mulheres, dos homossexuais, dos pobres, dos deficientes etc., além de aprofundar e ampliar os conhecimentos dos alunos mediante o confronto com outras representações e manifestações (NEIRA, 2011). Pelas lentes dessa perspectiva, as vertentes anteriormente defendidas na Educação Física ocultam as diferenças e os traços identitários, tornando-a em espaços racializados, genderizados e condicionados por questão de classe, sendo inviável o diálogo com as diferenças (NEIRA, 2018).

Inferimos, então, que a Educação Física foi atribuída por longos anos como instrumento de intervenção do Estado, sobretudo através da ingerência autoritária e repressiva deste, que tencionava a formação e manutenção de corpos disciplinados, fortes e saudáveis, cumprindo os interesses de cada período histórico. Destarte, as relações étnico-raciais foram invisibilizadas, marginalizadas e oprimidas em detrimento à reprodução de modelos eurocêntricos de manifestações da cultura corporal.

Concordamos com Moreira e Silva (2016, p. 54) quando expressam que

O estudo das relações étnico-raciais na Educação Física deve conduzir a uma reflexão
sobre o corpo e poder e, desvelar até que ponto estas relações influenciaram na produção
de estereótipos racistas. Defendemos também que corpo, movimento e cultura como
campos de estudos da Educação Física são temáticas que, potencializadas no currículo e
no projeto político-pedagógico podem colaborar para o reconhecimento das
desigualdades sociais, culturais e educacionais produzidas pelo fenômeno do racismo
assim como estancar seus efeitos que são contemporâneos (MOREIRA; SILVA, 2016,
p. 54).

Expandindo o debate para as possibilidades de trabalho da Educação Física - alicerçado à temática das relações étnico-raciais - é fundamental sublinhar o quanto elas são legítimas e reconhecidas por meio de medidas legais auferidas na área educacional. Diante disso, consideramos imprescindível apresentar nessa passagem o quanto as lutas das populações negras e indígenas estão (e estiveram) associadas às conquistas legais de muitos direitos.

Oliveira (2019) revela que as organizações do movimento negro como conhecemos hoje não se configuraram desde sempre desse modo. São, pois, diferentes associações que existem desde o século XVIII, que alteraram seus objetivos e suas características ao longo do tempo. Algumas 
dessas organizações foram precursoras no que diz respeito aos direitos educacionais e culturais, como a Frente Negra Brasileira - FNB, criada em 1931, considerada como o primeiro movimento racial realmente reivindicativo após a abolição da escravatura. Outra organização significativa foi o Teatro Experimental do Negro - TEN, fundado em 1944 por Abdias do Nascimento, possuía projetos que transitavam no campo político e educacional, e tinha objetivo de resgatar os valores da cultura negro-africana, propondo-se a combater o racismo através da arte e da educação (OLIVEIRA, 2009). Para Lima (2020), uma conquista fundamental na construção de espaços para reparações, também mobilizadas pelas ações dos movimentos negros, se deu pela inserção de pautas específicas na Constituição de 1988, como, por exemplo, a do reconhecimento da cultura como direito; do racismo como crime inafiançável e imprescritível e dos direitos da terra quilombola.

Concebendo a escola como espaço que reproduz os diversos problemas sociais - entre eles as desigualdades; o racismo; as diferentes discriminações - consideramos fundamental destacar a atuação dos movimentos político-sociais negros direcionada à esfera educacional.

\section{As principais conquistas educacionais auferidas pelos movimentos sociais}

A presença da população negra nas escolas revela que essas instituições estiveram, de fato, entre as ferramentas mobilizadas para sua afirmação no espaço social, visto que a educação é um dos principais instrumentos no processo de formação de qualquer sociedade.

No contexto dos mecanismos de desculturação da população afro-brasileira e dos currículos escolares - que potencializam a negação, ocultação e desvalorização da identidade, da história e da cultura afro-brasileira - é que as organizações negras posicionavam, e ainda posicionam, sua luta, principalmente pela garantia de políticas públicas educacionais, e intercedendo não apenas pelo direito ao acesso à educação, ao conhecimento e à escola pública, mas também à sua permanência e à qualidade desse conhecimento, reivindicando a inserção de suas histórias e culturas nos diálogos escolares. Entendemos que a finalidade desse confronto não se refere a mudanças do foco etnocêntrico do conhecimento - categoricamente eurocêntrico e estadunidense para o afro-brasileiro - mas sim à uma ampliação dos produtos dos currículos escolares, tencionando o trato das muitas diferenças, como culturais, raciais, sociais e econômicas.

Em Oliveira (2019), observamos a relevância da "III Conferência Mundial Contra o Racismo, Discriminação Racial, Xenofobia e Intolerância Correlata", realizada no ano de $2001 \mathrm{em}$ Durban - África do Sul para a discussão relativa às demandas educacionais da população negra aqui no Brasil. Nessa conjuntura, o país assumiu alguns compromissos de reparação, como a 
implementação de políticas de ações afirmativas, como, por exemplo, as cotas estudantis e cotas de emprego em segmentos da administração pública, em benefício dos negros, indígenas e outras minorias; a condenação da escravidão como crime contra a humanidade; a condenação do racismo; entre outros. Meira (2018, p. 46) afirma que a Conferência de Durban “[...] abriu definitivamente as portas para o reconhecimento das demandas urgentes a favor do povo negro no Brasil, entre elas uma educação que representasse de forma real a realidade da população negra".

Situada nesse cenário favorável à instituição de políticas educacionais, a Lei no 10.639 foi promulgada no ano de 2003, alterando a Lei no 9.394/96 de Diretrizes e Bases da educação nacional, tornando obrigatória a inclusão da "História e Cultura Afro-Brasileira" no currículo oficial da Rede de Ensino (BRASIL, 2003). Essa é considerada uma das medidas mais relevantes para estabelecer uma educação antirracista rumo à reparação humanitária do povo negro brasileiro, que impulsionou a temática para um novo patamar no contexto da educação brasileira. Enfatizamos aqui a ampla influência dos movimentos político-sociais da população negra para a criação dessa lei, pois tais organizações apontavam para a importância da presença de seus conhecimentos e culturas nas escolas há muitas décadas.

No intuito de subsidiar a consolidação da Lei 10.639/03, foram criadas em 2004, a partir do Parecer do Conselho Nacional de Educação CNE/CP 03/2004, as Diretrizes Curriculares Nacionais para a Educação das Relações Étnico-Raciais e para o Ensino de História e Cultura AfroBrasileira e Africana - DCN's ERER. São diretrizes que estabeleceram orientações, definições e princípios para a educação das relações étnico-raciais, especialmente no que tange o currículo da educação básica e da formação de professores.

Outro avanço se deu pela criação da Lei no 11.645 em 2008, que também alterou a Lei $n^{\circ}$ 9.394/96 de Diretrizes e Bases da educação nacional, incluindo no currículo oficial da Rede de Ensino a obrigatoriedade da temática "História e Cultura Afro-Brasileira e Indígena" (BRASIL, 2008).

\section{Breves considerações}

Admitimos que, para além do acesso, permanência e subsídios para o sucesso escolar, deve ser garantida à população negra e indígena a valorização de seu patrimônio histórico-cultural. Consentimos com a fala de Munanga (2015) ao apontar que para o fim do racismo, a saída não situa-se na erradicação da raça e dos processos de construção da identidade racial, mas sustenta-se em uma educação e socialização capazes de apontar a coexistência igualitária das diferenças e das identidades particulares. 
Argumentando particularmente acerca da Educação Física - disciplina curricular que intercedeu por muito tempo pelos interesses hegemônicos de cunho racista - defendemos a construção de currículos e práticas pedagógicas que lidem com os conhecimentos a partir de uma perspectiva decolonial, buscando a valorização dos saberes oriundos de diferentes populações, sobretudo daquelas que representam maioria numérica em nosso país, que foram historicamente silenciadas, e que encontram-se em constante (re)construção de suas manifestações, que são tão expressivas na formação da nossa identidade.

\section{Referências}

ABREU, Martha. O pós abolição e a luta antirracista no campo cultural. Curso de extensão "Emancipações e pós-abolição: por uma outra história do Brasil (1808-2020)". Org.:

Universidade Federal do Estado do Rio de Janeiro - Pró-Reitoria de Extensão e Cultura PROExC, 09/09/2020;

ALBUQUERQUE, Wlamyra Ribeiro de. Racialização e cidadania negra. Curso de extensão "Emancipações e pós-abolição: por uma outra história do Brasil (1808-2020)". Org.:

Universidade Federal do Estado do Rio de Janeiro - Pró-Reitoria de Extensão e Cultura PROExC,02/09/2020;

BRACHT, Valter. A constituição das teorias pedagógicas da educação física. Campinas: Cadernos Cedes, $n^{\circ}$ 48, 1999;

BRASIL. Lei no 10.639. Presidência da República. Casa Civil - Subchefia para Assuntos Jurídicos, 2003.Disponível em: < http://www.planalto.gov.br/ccivil_03/leis/2003/110.639.htm>;

BRASIL. Lei no 11.645. Presidência da República. Casa Civil - Subchefia para Assuntos Jurídicos, 2008.Disponível em:<http://www.planalto.gov.br/ccivil_03/Ato2007-

2010/2008/Lei/L11645.htm>. Acesso em: 11 Dez. de 2018;

CASTELLANI FILHO, Lino. Educação Física no Brasil: a história que não se conta. Campinas, SP: Papirus, $14^{\circ}$ ed., 2007;

LIMA, Mônica.Direito, reparação e a história africana e afro-brasileira no campo da história pública. Curso de extensão "Emancipações e pós-abolição: por uma outra história do Brasil (1808-2020)". Org.: Universidade Federal do Estado do Rio de Janeiro - Pró-Reitoria de Extensão e Cultura - PROExC, 23/09/2020;

MATTOS, Hebe.Escravidão, racismo e os sentidos da cidadania no processo de independência. Curso de extensão "Emancipações e pós-abolição: por uma outra história do Brasil (1808-2020)". Org.: Universidade Federal do Estado do Rio de Janeiro - Pró-Reitoria de Extensão e Cultura PROExC, 05/08/2020; 
MEIRA, Flávia Paola Félix. A Educação das Relações Étnico-Raciais no currículo de um curso de Pedagogia: percursos, contribuições e desafios. Dissertação de Mestrado - Faculdade de Educação, Universidade do Estado de Minas Gerais, Belo Horizonte, 2018;

MOREIRA, Anália de Jesus; SILVA, Maria Cecília de Paula. A Lei no 10.639/2003 e o ensino de Educação Física: confrontos históricos. In: CORSINO, Luciano Nascimento; CONCEIÇÃO, Willian Lazaretti da. Educação Física escolar e Relações Étnico-Raciais: subsídios para a implementação das Leis 10.639/03 e 11.645/08. Curitiba: CRV, 2016;

MUNANGA, Kabengele. Rediscutindo a mestiçagem no Brasil: identidade nacional versus identidade negra. Petrópolis, RJ: Vozes, 1999;

MUNANGA, Kabengele. Por que ensinar a história da África e do negro no Brasil de hoje? Revista do Instituto de Estudos Brasileiros, nº 62, p. 20-31, dez 2015;

NEIRA, Marcos Garcia. Teorias pós-críticas da educação: subsídios para o debate curricular da Educação Física. Dialogia, São Paulo, SP: no 14, p. 195-206, 2011;

NEIRA, Marcos Garcia. O currículo cultural da Educação Física: pressupostos, princípios e orientações didáticas. Revista e-Curriculum, São Paulo, SP: vol. 16, nº 1, p. 4-28, 2018;

OLIVEIRA, Julvan Moreira de. Africanidades e Educação: Ancestralidade, Identidade e Oralidade no Pensamento de Kabengele Munanga. Tese de Doutorado - Faculdade de Educação, Universidade de São Paulo, São Paulo, 2009;

OLIVEIRA, Julvan Moreira de. Políticas Públicas e Ensino de História da África e Cultura Afrobrasileira. In: THOMAZ, Fernanda do Nascimento (Org.). Afrikas: histórias, culturas e educação. Juiz de Fora, Ed. UFJF, 2019;

PINTO, Ana Flávia Magalhães.Liberdade negra e abolicionismos.Curso de extensão "Emancipações e pós-abolição: por uma outra história do Brasil (1808-2020)". Org.: Universidade Federal do Estado do Rio de Janeiro - Pró-Reitoria de Extensão e Cultura PROExC,26/08/2020;

SILVA, Leandro de Souza. Educação das Relações Étnico-Raciais nos cursos de licenciatura em Educação Física no Mato Grosso do Sul. Dissertação de Mestrado, Faculdade de Educação, Universidade Federal da Grande Dourados, Dourados, MS, 2019;

SOARES, Carmen Lúcia. Educação Física: raízes européias e Brasil. $4^{\circ}$ edição. Campinas, SP: Autores Associados, 2007.esso em: 01 jun. 2020. 